\title{
Game-Theoretic Approach to Bank Loan Repayment
}

\author{
Andrzej Paliński*
}

\begin{abstract}
This paper presents a model of bank-loan repayment as a signaling game with a set of discrete types of borrowers. The type of borrower is the return on an investment project. A possibility of renegotiation of the loan agreement leads to an equilibrium in which the borrower adjusts the repaid amount to the liquidation value of its assets (from the bank's point of view). In the equilibrium, there are numerous pooling equilibrium points, with values rising according to the expected liquidation value of the loan. The article additionally proposes a mechanism forcing the borrower to pay all of his return instead of the common liquidation value of subset of types of the borrower. The paper contains also a simple numerical example explaining this mechanism.
\end{abstract}

Keywords: bank, loan, credit agreement, repayment, renegotiation, game theory

Mathematics Subject Classification: 91A28, 91A80, 91B44

JEL Classification: C72, D86, G21

Revised: July 15, 2015

\section{INTRODUCTION}

A bank, granting a loan, has no possibility of influencing its actual spending; hence, a precise credit agreement should be signed. The main elements of a loan agreement are: the amount of the loan, the amount of repayment and collateral. Due to the asymmetry of information, a necessary component of the loan agreement is collateral, imposing on the debtor an incentive to repay the loan. However, the option to renegotiate the loan agreement, changes the relationship between the bank and the borrower.

The possibility of renegotiation inclines the borrower to transfer a part of the risk to the lender. The research belonging to the theory of incomplete contracts suggest that the borrower renegotiate a contract or even does not make repayment if the liquidation value of collateral is low. This idea is incorporated, among others, in the works of: Aghion and Bolton (1992), Bester (1994), Hart and Moor (1994 and 1998), Bolton and Scharfstein (1996), Lacker (2001) and Paliński (2013).

* AGH University of Science and Technology, Faculty of Management, Krakow, Poland, e-mail: palinski@zarz.agh.edu.pl 
According to this research, the liquidation value of collateral determines not only the amounts recovered by the bank in the absence of repayment of the loan, but also affects the results of renegotiation of the debt. This is due to the fact that the threat of liquidation of assets motivates the borrower to avoid insolvency; consequently, the liquidation value determines the amount of debt repayment. When the liquidation value is low - the bargaining power of the borrower increases and the amount of debt repayment reduces.

The main aim of this article is to analyze a model of loan repayment as a signaling game in which the borrower sends a signal - a proposed amount of repayment whereas the bank receives the signal and takes action - accepts or rejects the proposal (Cho and Kreps, 1987; Fudenberg and Tirole, 1991). Depending on the liquidation value of the borrower's assets, the possibility of the debt renegotiation plays a crucial role in the model. The presented model refers to the issue of the role of collateral for the repayment of the loan and the renegotiation considered by Bester (1994). In addition, a voluntary repayment of the loan is assumed in the model, in which the borrower determines the amount of repayment, trying to avoid enforcement of the debt. This approach refers to models of Krasa-Villamil (2000) and Krasa-Sharma-Villamil (2005).

The remainder of this paper is organized as follows: Section 2 presents the assumptions of the model and the analysis of the equilibrium in the model. Section 3 contains a proposition of an incentive mechanism, motivating the borrower to repay the highest possible amount. Section 4 provides main conclusions.

\section{THE MODEL}

Consider an economy with two risk neutral agents: an entrepreneur and a bank (their indexes are, respectively, $E$ and $B$ ). Assume that the entrepreneur signed a credit agreement with the bank to finance a venture. The credit agreement $\left(I, R_{1}, C\right)$ with the bank is a triplet that with a given amount of the loan $I$ determines the amount of repayment $R_{1}$ and collateral $C$. Loan repayment $R_{1}$ is independent of realization of the project; thus, we assume that the credit agreement as a standard debt contract (SDC) with collateral. The standard debt contract is a contract in which a borrower agrees to pay a fixed amount, and non-payment allows a bank to seize the borrower's assets being the output of the project.

The return of the project is a random variable $Y$ with discrete realizations $\mathrm{y} \in \mathrm{W}=\{0, \ldots, \overline{\mathrm{y}}\} \subset \mathbb{R}_{+}$, where $\overline{\mathrm{y}}>0$, with cumulative distribution $F(y)$. This return of the project is observable without costs only to the entrepreneur, what is known to both agents before signing the agreement. Agents have common knowledge of the prior beliefs $\beta(\cdot)$ on the set of possible realizations of $Y$, where $\beta(y)>0$.

In case of default, the entrepreneur can turn to the bank for debt restructuring involving a cancellation of the debt. The bank may restructure the debt or seize collateral together with the venture.

The value of collateral is lower for the bank than for the borrower because of the cost of acquisition and liquidation, and is $b C$, where $0 \leq b<1$. Similarly, the acquisition and management of the project generates considerable costs, thus the value 
of the project for the bank is $a Y$, where $0 \leq a<1$. Assume further that $b C \leq R_{1}$, which means that the bank does not have collateral exceeding the value of the loan. Assume also a reservation utility of the bank $\bar{u}$, which can be positive for an insolvent borrower or negative for a promising borrower. Let us define the value of the borrower's asset from the bank's point of view in the case of default as follows.

Definition 2.1. The value $L(y)=a y+b C+\bar{u}$ is called the liquidation value of loan. After signing the credit agreement $\left(I, R_{1}, C\right)$ in period $t=0$, the game of loan repayment is as follows.

1) In the first period $t=1$, nature selects the return of the project $y$.

2) In the next period $t=2$, the entrepreneur observes the realization of the project. Knowing the return of the project the entrepreneur decides to make voluntary payment $v \in V=[0, \bar{y}] \subset \mathbb{R}_{+}$. If $v<R_{1}$, then the entrepreneur declares default and counts on debt forgiveness. The pure strategy of the entrepreneur is the payment $v$ made after observing the return of the project $y$. The decision on the payment $v$ can no longer be changed at a later date (due to the inclusion of relevant data in financial books).

3) In the last period $t=3$, the bank observes proposed $v$, but does not know the true state of nature. When $v<R_{1}$, the bank decides whether to restructure the debt and sign a new credit agreement $(I, v, C)$ or to seize the project with collateral. If proposed $v=R_{1}$, the bank accepts payment in accordance with the credit agreement. The behavior strategy of the lender $\sigma_{B} \in \sum_{B}=[0,1]$ is the probability of loan restructuring and acceptance of payment $v$. The strategy $\sigma_{B}=1$ means the acceptance of the payment $v$; moreover, if $v<R_{1}$ - this means a new contract and partial cancellation of the debt on amount $x=R_{1}-v$. While $\sigma_{B}=0$ means the liquidation of the loan.

Expected payoff of the entrepreneur $E \pi_{E}$ and the bank $E \pi_{B}$ for the pair of strategies $v$ and $\sigma_{B}$ after observing the return $y$ by the entrepreneur are as follows:

$$
\mathrm{E}_{v, \sigma_{\mathrm{B}}} \pi_{E}\left(y, v, \sigma_{B}\right)=\sigma_{B}(y-v)-\left(1-\sigma_{B}\right) C
$$

and:

$$
\mathrm{E}_{\sigma_{\mathrm{B}}} \pi_{B}\left(y, \nu, \sigma_{B}\right)=\sum_{y \in W} \beta(y \mid v)\left[\sigma_{B} v+\left(1-\sigma_{B}\right)(a y+b C)\right]
$$

An updated belief $\beta(y \mid v)$ is the probability assigned by the bank to the type of the entrepreneur $y$ after observing the proposed payment $v$.

Definition 2.2. A strategy profile $v, \sigma_{B}$ along with beliefs $\beta(y), \beta(y \mid v)$ is a perfect Bayesian equilibrium if and only if:

(i) $v \in V$ maximizes $E_{v, \sigma_{B}} \pi_{E}\left(y, v, \sigma_{B}\right)$ for every $y$.

(ii) $\sigma_{B} \in \sum_{B}$ maximizes $E_{\sigma_{B}} \pi_{B}\left(y, v, \sigma_{B}\right)$ for every $v$.

(iii) $\beta(y \mid v)=\frac{v(y) \beta(y)}{\sum_{y^{\prime} \in Y}\left[v\left(y^{\prime}\right) \beta\left(y^{\prime}\right)\right]}$ if it is possible. Otherwise $\beta(y \mid v)$ is any probability on $\{y \in W \mid y \geq v\}$. 
Conditions (i) and (ii) impose a requirement that each strategy was perfect Bayesian equilibrium for each subgame with some beliefs. The return on the project $y$ is, at the same time, the type of entrepreneur in the game. Condition (iii) specifies how to update beliefs after observing the amount of repayment $v$ using Bayes's rule (Bayes, Price, 1763; see: Fudenberg and Tirole, 1991).

The entrepreneur, knowing the return on the project $y$ and deciding to make a payment $v$, has to solve the following problem.

Problem 2.1. At time $t=2$ find $v$ and $\sigma_{B}$ to solve the following optimization problem

$$
\max _{v, \sigma_{B}} E_{v, \sigma_{B}} \pi_{E}\left(y, v, \sigma_{B}\right)
$$

subject to:

$$
\begin{aligned}
& E_{\sigma_{B}} \pi_{B}\left(y, v, \sigma_{B}\right) \geq \sum_{y \in W} \beta(y \mid v) \min \left\{R_{1}, L(y)\right\} \text { for each } y, \\
& \text { having } \beta(y \mid v)>0 \\
& 0 \leq v \leq y \text { and } v \leq R_{1} \text { for all } y \\
& v, \sigma_{B}, \beta(y), \beta(y \mid v) \text { are a perfect Bayesian equilibrium at } t=3
\end{aligned}
$$

The individual rationality constraint of the bank (4) indicates that in case of payment lower than the payment $R_{1}$ required by the credit agreement the bank in the worst case is assured of the expected liquidation value of the loan.

Condition (5) imposes a requirement on the voluntary payment $v$ that it be no greater than the return on the project $y$ and does not exceed $R_{1}$.

Definition 2.3. Let $y_{k} \in W$ is an arbitrary chosen type of the borrower. The expected liquidation value of the loan, $E L_{k}$, for types $y \in W, y \geq \underline{y_{k}}$, is defined as follows:

$$
E L_{k}=\max _{y \in W} \frac{\sum_{y \geq \underline{y_{k}}} \beta(y)(a y+b C+\bar{u})}{\sum_{y \geq \underline{y_{k}}} \beta(y)} \leq \underline{y_{k}}
$$

where $\underline{y_{1}}=\min _{y \geq \frac{b C+u}{(1-a)}} y, \underline{y_{k+1}}=\min _{y>\underline{y_{k}}} y$ such that $E L_{k}>\underline{y_{k}}, k=1,2,3, \ldots, n$.

The expected liquidation value $E L_{k}$ is defined as the maximum expected value of liquidation of some subset of types greater or equal than $y_{k}$, for which this value is not greater than the return on the project of the lowest type $y_{k}$ in the subset. The $y_{k}$ belongs to a discrete set of types, whereas the expected liquidation value $E L_{k}$ is a real number; therefore, there is a weak inequality in formula (7). The next expected liquidation value $E L_{k+1}$ can be calculated for a subset of types greater than the largest type in the previous subset. 
Proposition 2.1. The solution of Problem 2.1 is the following perfect Bayesian equilibrium in which

1) The strategy of the borrower is:

$$
v(y)= \begin{cases}0, & y<\frac{b C+\bar{u}}{(1-a)}, \\ E L_{k}, & \frac{b C+\bar{u}}{(1-a)} \leq y<\frac{R_{1}-b C-\bar{u}}{a}, k=1,2,3, \ldots, n, \\ R_{1}, & y \geq \frac{R_{1}-b C-\bar{u}}{a} .\end{cases}
$$

2) The strategy of the bank is:

$$
\sigma_{B}(v)=\left\{\begin{array}{l}
0, \quad v<\frac{b C+\bar{u}}{(1-a)} \\
1, \quad v \geq \frac{b C+\bar{u}}{(1-a)}
\end{array}\right.
$$

Proof. Consider a borrower whose return is less than his liquidation value of the loan $L(y)$, that is $y<a y+b C+\bar{u}=L(y)$. Such borrower is able to pay $v \leq y<L(y)$. An updated belief of the borrower's type is $\beta(y<(b C+\bar{u}) /(1-a) \mid v)=1$, so the strategy of the bank is liquidation $\sigma_{B}=0$ and the strategy of the borrower is not to pay, which satisfies conditions (i) and (ii) of Definition 2.2.

Consider a borrower $y_{1} \in W$, whose return is equal to or greater than his liquidation value, such that $\underline{y_{1}}=\min \frac{b C+\bar{u}}{1-a} \leq y \leq \bar{y} y$. He is able to pay $v \geq$ $(b C+\bar{u}) /(1-a)$ to avoid liquidation. Consider further types of borrower $y \in$ $\left\{\underline{y_{1}}, \ldots, \overline{y_{1}}\right\} \subset\left[\frac{b C+\bar{u}}{1-a}, \bar{y}\right]$, where $\overline{y_{1}} \geq \underline{y_{1}}$, for which the expected liquidation value is $\frac{1}{\sum_{y \in\left\{\underline{y_{k}}, \ldots, \overline{y_{k}}\right\}} \beta(y)}\left[\sum_{y \in\left\{\underline{y_{1}}, \ldots, \overline{y_{1}}\right\}} \beta(y) a y+b C+\bar{u}\right]=E L_{1} \leq \underline{y_{1}}$. Rather than pay an amount equal to their return on investment $y$ (which will give them an income equal zero), they can pretend a lower return and pay $v=E L_{1}$, which gives them $y-E L_{1} \geq 0$. On the basis of the proposed repayment $v$, the bank is not able to distinguish the type of borrower and an updated belief is $\beta\left(y \geq(b C+\bar{u}) /(1-a) \mid v=E L_{1}\right)=1$. As the expected liquidation value is $E L_{1}=v$, the bank will accept this payment, and will use a strategy $\sigma_{B}(v)=1$. Liquidation would give the bank no more.

None of the types of borrower can individually change the strategy to repay less than the liquidation value of the common $E L_{1}$, even if its own liquidation value is below the common value $E L_{1}$, because in the absence of correlation with other types, this would reduce the value of the repayment below the expected liquidation value. In case $E L_{1}>v$, the bank would prefer liquidation and repayment $v$ less than the liquidation value $E L_{1}$ by the borrower of any type would result in the change of bank's strategy to $\sigma_{B}(v)=0$, which would give the borrower income $-C$. Hence, repayment $v<E L_{1}$ is not the optimal strategy of the borrower. 
Consequently, both strategies satisfy conditions (i) and (ii) of Definition 2.2. There exist conditions for pooling equilibrium in which borrower of types $y \in\left\{\underline{y_{1}}, \ldots, \overline{y_{1}}\right\}$ pay the same amount $v=E L_{1}$.

If, however, the expected liquidation value of the loan $E L_{1}$ for all types of $y \geq(b C+\bar{u}) /(1-a)$ was greater than $y_{1}$, then for types $y>\overline{y_{1}}$ must be created another equilibrium $v=E L_{2}>y_{1} \geq E \overline{L_{1}}$ providing loan restructuring. Otherwise, the bank would prefer to liquidate, giving him a higher expected payoff, rather than restructuring the debt.

This reasoning should be repeated for the next $E L_{k}$ until the expected liquidation value of the loan for a certain type $y$ exceeds repayment $R_{1}$ required in the loan agreement. Substituting $y$ with $R_{1}$ in the formula of the liquidation value we get $y \geq\left(R_{1}-b C-\bar{u}\right) / a$. Above this value, the borrower repays the amount $v=R_{1}$, and the bank has to accept payment according to the loan agreement.

Figure 1 depicts a diagram of debt repayment depending on the amount of return on the project resulting from Proposition 2.1. Repayment of the loan $R_{1}$, specified in the loan contract, begins not when return is $y=R_{1}$, but when the expected liquidation value of the loan is equal to $R_{1}$, that is for $y$ satisfying the inequality $a y+b C+\bar{u} \geq R_{1}$.

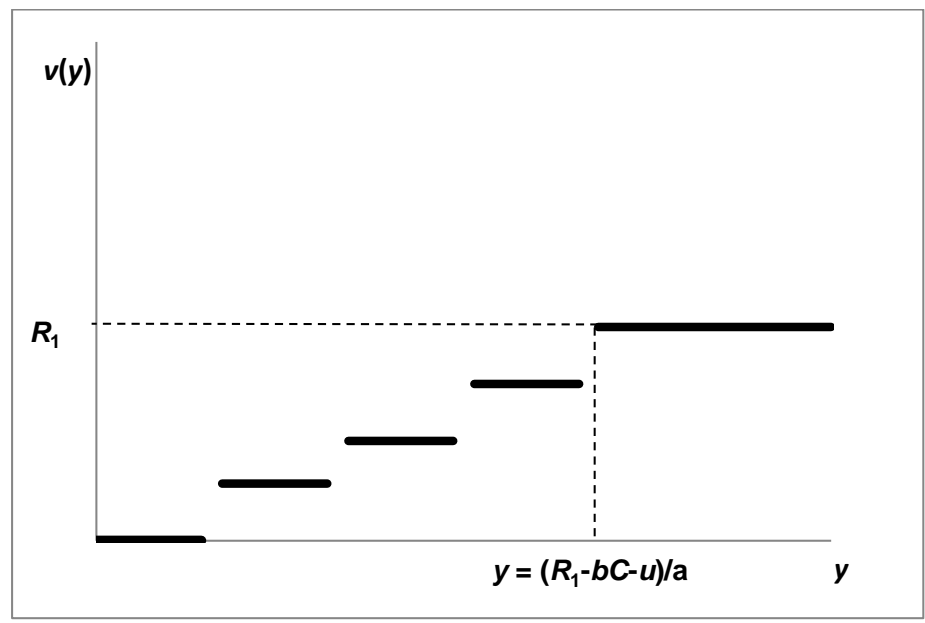

Fig. 1. Loan repayment diagram resulting from Proposition 2.1

\section{EXTENSION OF THE MODEL - FUTURE LOANS}

There exists a great amount of literature the on so-called relationship lending. Such a term covers the economic value of long-term cooperation between a bank and a borrower - an important role in this field plays the model of Rajan (1992) (see Boot, 2000 for overview of the models; examples of empirical studies can be found in works of: Petersen and Rajan, 1994, Degryse, 2000, Bharath et al., 2007). Omitting complex interdependencies of such relationship, each entrepreneur thinking about further operating activity, needs future loans. 
Let us assume that the enterprise - current borrower - has ability to run next project that can give him the expected payoff $E \pi_{2}$. The enterprise requires external sources of financing to run this project. Taking into account the finding of Proposition 2.1. we would like to construct a mechanism that would force the borrower to pay all his return on the first project instead of the expected liquidation value. If we made the probability of granting the next loan by the incumbent bank dependent on the amount repaid for the first loan we would achieve the mechanism of true payment.

Assumption 3.1. Let $m$ be the probability of granting the next loan. Correct mechanism $m(v)$ depending on the amount of the repayment of the previous loan must meet the following conditions:

1) Repayment $v \leq(b C+\bar{u}) /(1-a)$ means taking over collateral and usually results in bankruptcy of the borrower - not giving a chance to grant another loan, i.e. $m(v \leq(b C+\bar{u}) /(1-a))=0$.

2) Repayment required in the loan agreement and equal to $R_{1}$ is reworded in certainty of getting another loan, i.e. $m\left(v=R_{1}\right)=1$.

3) Repayment between these extreme values $v \in\left(\frac{b C+\bar{u}}{1-a}, R_{1}\right)$ allows for another loan with the probability that is a linear function of the repaid amount on the interval specified by extreme values. This is due to the fact that a standard debt contract for $y<R_{1}$ is a linear function of the return on the business venture and is $R(y)=y$ (cf. Gale and Helwig, 1985).

Condition 3) should ensure that $v(y)=y$.

Lemma 3.1. The mechanism satisfying Assumption 3.1. is described by the following function:

$$
m(v)= \begin{cases}0, & v<\frac{b C+\bar{u}}{(1-a)} \\ \frac{v-\frac{b C+\bar{u}}{1-a}}{R_{1}-\frac{b C+\bar{u}}{1-a}}, & v \geq \frac{b C+\bar{u}}{(1-a)}\end{cases}
$$

Proof.

(1) $m\left(v=\frac{b C+\bar{u}}{1-a}\right)=0$.

(2) $m\left(v=R_{1}\right)=1$.

(3) The function $m(v)$ is linear for $v \in\left[\frac{b C+\bar{u}}{1-a}, R_{1}\right]$.

The effectiveness of such a mechanism to incentivize the borrower to allocate the total return on the project $y$ for repayment of the loan will depend on the value of the expected return on the next investment project $E \pi_{2}$. The expected value of a new project from the point of view of the entrepreneur is also dependent on the probability of granting the next loan, without which it will be impossible to undertake the project due to a lack of funds.

Proposition 3.1. Mechanism $m(v)$ is effective when:

$$
E \pi_{2} \geq \frac{1}{1-a}\left[R_{1}-L\left(R_{1}\right)\right]
$$


Proof. According to Proposition 2.1., some types of borrower try to form pooling equilibrium $v$, for which their total expected liquidation value is no less than their possible payment $v$. The payment $v$ is lower than or equal to return $y$ for each type forming the pooling equilibrium.

To avoid forming an equilibrium, it is necessary for each type of borrower that the expected value of payoff from the next investment project after repayment of the whole return of the current project $y$ is not less than the excess return $y$ over the payment $v$. For this purpose two conditions must be fulfilled:

1) $m(y) E \pi_{2} \geq y-L(y)$, for each $\frac{b C+\bar{u}}{1-a} \leq y \leq R_{1}$.

2) $\left[m\left(y^{\prime \prime}\right)-m\left(y^{\prime}\right)\right] E \pi_{2} \geq y^{\prime \prime}-y^{\prime}$, for each $y^{\prime \prime}>y^{\prime}$, where $y^{\prime \prime}, y^{\prime} \in W, \frac{b C+\bar{u}}{1-a} \leq$ $y^{\prime} \leq R_{1}, \frac{b C+\bar{u}}{1-a} \leq y^{\prime \prime} \leq R_{1}$.

The first condition is that the lowest possible payment $v$ equal to the expected liquidation value for any type is not profitable. The second condition implies that if $E L\left(y^{\prime \prime}\right) \geq y^{\prime}$, the strategy of pretending lower return and payment $v=y^{\prime}$ is also unprofitable.

Starting from Condition (1) and substituting $m(v)$ with function from Lemma 3.1., we have:

$$
m(y) E \pi_{2}=\frac{y-\frac{b C+\bar{u}}{1-a}}{R_{1}-\frac{b C+\bar{u}}{1-a}} E \pi_{2} \geq y-L(y)=y-a y+b C+\bar{u}
$$

which, after transformation, gives:

$$
E \pi_{2} \geq(1-a) R_{1}-b C-\bar{u}=R_{1}-L\left(R_{1}\right)
$$

Considering Condition (2) we have:

$$
\left[m\left(y^{\prime \prime}\right)-m\left(y^{\prime}\right)\right] E \pi_{2}=\left[\frac{y^{\prime \prime}-\frac{b C+\bar{u}}{1-a}}{R_{1}-\frac{b C+\bar{u}}{1-a}}-\frac{y^{\prime}-\frac{b C+\bar{u}}{1-a}}{R_{1}-\frac{b C+\bar{u}}{1-a}}\right] E \pi_{2} \geq y^{\prime \prime}-y^{\prime}
$$

Rearranging we get:

$$
\left(y^{\prime \prime}-y^{\prime}\right) E \pi_{2} \geq\left(y^{\prime \prime}-y^{\prime}\right)\left(R_{1}-\frac{b C+\bar{u}}{1-a}\right)
$$

which leads to:

$$
E \pi_{2} \geq R_{1}-\frac{b C+\bar{u}}{1-a}=\frac{1}{1-a}\left[(1-a) R_{1}-b C-\bar{u}\right]
$$

and finally gives:

$$
E \pi_{2} \geq \frac{1}{1-a}\left[R_{1}-L\left(R_{1}\right)\right]
$$

Since $1 /(1-a) \geq 1$, Condition (2) imposes a higher or equal value on $E \pi_{2}$ than Condition (1); therefore, Condition (2) is binding. 
Mechanism $m(v)$ appears to be effective when the expected payoff from a future project is not less than the difference between the repayment under a loan agreement $R_{1}$ and the repayment of the liquidation value for $y$ equal to repayment $R_{1}$ multiplied by the reciprocal of the coefficient of the loss of value of the project. In the case of the standard debt contract return on the project $y=R_{1}$ is the border point, below which there is an area of insolvency.

The result of Proposition 3.1. is not very optimistic. The expected value of a new project planned by the borrower must be high so that the borrower would spend the whole return from the first project to repay the loan. This is illustrated by a simple numerical example. Let us take the following assumptions: $R_{1}=100, C=100, \bar{u}=0$. The minimum $E \pi_{2}$, value depending on the recovery coefficients $a$ and $b$, is shown in Table 1.

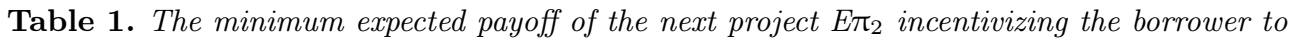
repay the first loan depending on recovery coefficients $a$ and $b$

\begin{tabular}{|c|c|c|c|c|c|c|c|c|c|c|}
\hline & \multicolumn{9}{|c|}{ Coefficient $a$} \\
\hline & & 0.1 & 0.2 & 0.3 & 0.4 & 0.5 & 0.6 & 0.7 & 0.8 & 0.9 \\
\hline \multirow{9}{*}{ 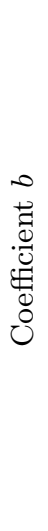 } & 0.1 & 88.89 & 87.50 & 85.71 & 83.33 & 80.00 & 75.00 & 66.67 & 50.00 & - \\
\hline & 0.2 & 77.78 & 75.00 & 71.43 & 66.67 & 60.00 & 50.00 & 33.33 & - & - \\
\hline & 0.3 & 66.67 & 62.50 & 57.14 & 50.00 & 40.00 & 25.00 & - & - & - \\
\hline & 0.4 & 55.56 & 50.00 & 42.86 & 33.33 & 20.00 & - & - & - & - \\
\hline & 0.5 & 44.44 & 37.50 & 28.57 & 16.67 & - & - & - & - & - \\
\hline & 0.6 & 33.33 & 25.00 & 14.29 & - & - & - & - & - & - \\
\hline & 0.7 & 22.22 & 12.50 & - & - & - & - & - & - & - \\
\hline & 0.8 & 11.11 & - & - & - & - & - & - & - & - \\
\hline & 0.9 & - & - & - & - & - & - & - & - & - \\
\hline
\end{tabular}

Under normal economic conditions, most common recovery rates are of $0.2-0.5$, the profitability of assets is equal from several to more than ten percent, and the share of debt in financing a project is about half of the investment funds. In this situation, the next business project would have to be several times larger than the previous project to ensure the required expected payoff, which is hardly possible in practice.

\section{CONCLUSIONS}

The key role for the repayment of the bank loan plays the liquidation value of assets of the borrower. In the game of loan repayment, a perfect Bayesian equilibrium is formed from a plurality of pooling equilibria in which the amount of the repayment of the loan is equal to the common expected liquidation value of several types. Each 
following point of pooling equilibrium is created by a subset of types of the borrower with a higher common expected liquidation value.

We can construct a mechanism motivating the borrower to use the total return on the investment project to repay the loan, if the repayment is not in accordance with the loan agreement. This mechanism is based on the dependence of the probability of granting a future loan on the repayment of the former loan. Unfortunately, the effectiveness of this mechanism is limited by the high expected value of the future investment project.

\section{REFERENCES}

Aghion, P., Bolton, P., 1992. An Incomplete Contracts Approach to Financial Contracting. Review of Economic Studies, 59(3), pp. 473-494.

Bayes, T., Price, R., 1763. An Essay towards solving a Problem in the Doctrine of Chance. By the late Rev. Mr. Bayes, communicated by Mr. Price, in a letter to John Canton, A. M. F. R. S. Philosophical Transactions of the Royal Society of London, 53(0), pp. 370-418.

Bester, H., 1994. The Role of Collateral in a Model of Debt Renegotiation. Journal of Money, Credit and Banking, 26(1), pp. 72-86.

Bharath, S., Dahiya, S., Saunders, A., Srinivasan, A., 2007. So what do I get? The bank's view of lending relationships. Journal of Financial Economics, 85, pp. 368-419.

Bolton, P., Scharfstein, D., 1996. Optimal Debt Structure and the Number of Creditors. The Journal of Political Economy, 104(1), pp. 1-25.

Boot, A., 2000. Relationship Banking: What Do We Know? Journal of Financial Intermediation, 9, pp. 7-25.

Cho, I., Kreps, D., 1987. Signaling Games and Stable Equilibria. The Quarterly Journal of Economics, 102(2), pp. 179-222.

Degryse, H., 2000. Relationship Lending within a Bank-Based System: Evidence from European Small Business Data. Journal of Financial Intermediation, 9, pp. 90-109.

Fudenberg, D., Tirole, J., 1991. Game theory. The MIT Press, Cambridge, London.

Gale, D., Hellwig, M., 1985. Incentive-compatible Debt Contracts. The One-Period Problem. The Review of Economics Studies, 52, pp. 647-663.

Hart, O., Moore, J., 1994. A Theory of Debt Based on the Inalienability of Human Capital. The Quarterly Journal of Economics, 109(4), pp. 841-879.

Hart, O., Moore, J., 1998. Default and renegotiation: a dynamic model of debt. The Quarterly Journal of Economics, 113(1), pp. 1-41.

Krasa, S., Villamil, A., 2000. Optimal Contracts when Enforcement is a Decision Variable. Econometrica, 68(1), pp. 119-134.

Krasa, S., Sharma, T., Villamil A., 2005. Debt contracts and cooperative improvements. Journal of Mathematical Economics, 41, pp. 857-874.

Lacker, J., 2001. Collateralized Debt as the Optimal Contract. Review of Economic Design, 4, pp. 842-859.

Paliński, A., 2013. Loan Payment and Renegotiation: The Role of the Liquidation Value, SSRN Working Papers, URL http://ssrn. com/abstract=2325424.

Petersen, M., Rajan, R., 1994. The benefits of lending relationships: Evidence from small business data. Journal of Finance, 49, pp. 3-37.

Rajan, R., 1992. Insiders and outsiders. The choice between informed and arm's length debt. Journal of Finance, 47, pp. 1367-1400. 